Article

\title{
Catalytic epoxidation of cyclohexene over mesoporous-silica immobilized Keggin-type tungstophosphoric acid
}

\author{
CAI Wenjia, ZHOU Yan, BAO Renlie, YUE Bin *, HE Heyong \# \\ Department of Chemistry and Shanghai Key Laboratory of Molecular Catalysis and Innovative Materials, Fudan University, Shanghai 200433, China
}

\section{A R T I C L E I N F O}

\section{Article history:}

Received 31 August 2012

Accepted 18 September 2012

Published 20 January 2013

\section{Keywords:}

12-phosphotungstic acid

Aminosilylation

SBA-15

Epoxidation

Cyclohexene

\begin{abstract}
A B S T R A C T
A series of aminosilylated mesoporous silica (SBA-15) samples with different contents of (3-aminopropyl)triethoxysilane (APTES), synthesized using a simple one-pot method, were used as hosts for immobilization of Keggin-type 12-phosphotungstic acid $\left(\mathrm{H}_{3} \mathrm{PW}_{12} \mathrm{O}_{40}\right)$. The loading of $\mathrm{H}_{3} \mathrm{PW}_{12} \mathrm{O}_{40}$ increased with increasing content of grafted APTES. The obtained materials were calcined at different temperatures, and the tungsten species were highly dispersed inside the SBA-15 channels. The catalytic activities of these samples were tested in heterogeneous oxidation of cyclohexene using $\mathrm{H}_{2} \mathrm{O}_{2}$ as the oxidant. The effects of different loadings and treatment temperatures on the activities of the catalysts were also investigated. The catalysts calcined at $400{ }^{\circ} \mathrm{C}$ showed high catalytic activities and reusabilities.
\end{abstract}

(C) 2013, Dalian Institute of Chemical Physics, Chinese Academy of Sciences. Published by Elsevier B.V. All rights reserved.

\section{Introduction}

Tungsten-based catalysts have attracted much interest because they exhibit excellent catalytic activities in various reactions, such as epoxidation of alkenes [1-7], selective oxidation of alcohols [8-11], oxidative cleavage of olefins [12], and oxidative desulfurization of sulfur-containing organics [13]. Among these catalysts, materials based on Keggin-type 12-phosphotungstic acid $\left(\mathrm{H}_{3} \mathrm{PW}_{12} \mathrm{O}_{40}\right)$ have been extensively studied because of their high activity [14-23]. However, the high solubility of $\mathrm{H}_{3} \mathrm{PW}_{12} \mathrm{O}_{40}$ in water and polar organic solvents and the low surface area of $\mathrm{H}_{3} \mathrm{PW}_{12} \mathrm{O}_{40}$ limit practical applications. Heterogenization of the heteropoly acid is a feasible way of solving these problems. There have been a number of reports of heteropoly acids being highly dispersed on oxide supports such as $\mathrm{SiO}_{2}, \mathrm{ZrO}_{2}$, and $\mathrm{TiO}_{2}$ [24-28]. In terms of "green chemistry", however, high activity of the catalyst is not the only concern, and good reusability and environmental friendliness are equally important.

Mesoporous silica SBA-15, which has an adjustable pore size and high thermal stability, is regarded as a good support for the accommodation of catalytic active species [29,30]. Furthermore, it is well documented that the surface of SBA-15 can be easily modified with different functional groups. Recently, the grafting of (3-aminopropyl)triethoxysilane (APTES) onto a silica surface was reported as a post-modification method for the introduction of functional amino groups onto a silica surface [31-33]. The surface-bonded amino groups can be used as a base to firmly anchor acidic species, e.g., iso- and hetero-poly acids, on the silica surface through electrostatic interactions [34,35].

Compared with the above conventional grafting method, the co-synthesis method offers a direct and easy way of modifying the surface of a mesoporous material in one pot by the copoly-

\footnotetext{
* Corresponding authors. Tel: +86-21-65642779; Fax: +86-21-55665572; E-mail: yuebin@fudan.edu.cn

\# Corresponding authors. Tel: +86-21-65643916; Fax: +86-21-55665572; E-mail: heyonghe@fudan.edu.cn

This work was supported by the National Basic Research Program of China (973 Program, 2009CB623506), the National Natural Science Foundation of China (21173050), and Shanghai Leading Academic Discipline Project (B108).

DOI: $10.1016 / \mathrm{S} 1872-2067(11) 60459-2$
} 
merization of an organosilane with silica or organosilica precursors in the presence of a surfactant. This approach provides a higher content of functional organosilane groups. It is expected that as a result of the strong interactions between amino groups and polyacid species, the immobilized heteropoly acid/mesoporous silica composite materials will exhibit satisfactory reactivities and anti-leaching properties in epoxidation reactions involving $\mathrm{H}_{2} \mathrm{O}_{2}$.

In this work, $\mathrm{H}_{3} \mathrm{PW}_{12} \mathrm{O}_{40}$ was immobilized on one-pot- synthesized aminosilylated mesoporous silica SBA-15 with various organosilane contents. The as-synthesized samples were characterized using various techniques, including X-ray diffraction (XRD), $\mathrm{N}_{2}$ adsorption-desorption, transmission electron microscopy (TEM), nuclear magnetic resonance (NMR), and infrared (IR) spectroscopy. The effects of tungsten species loading and calcination temperature on the SBA-15 structure were investigated. In a model reaction, cyclohexene epoxidation with $\mathrm{H}_{2} \mathrm{O}_{2}$ as an oxidant, the SBA-15-incorporated tungstic species displayed high reactivity combined with good reusability.

\section{Experimental}

\subsection{Preparation}

The APTES-functionalized SBA-15 samples were synthesized according to the literature method [36,37]. Four grams of a surfactant, poly(ethylene glycol)-block-poly(propylene glycol)-block-poly(ethylene glycol) (P123), were dissolved in 125 $\mathrm{g}$ of $2.0 \mathrm{~mol} / \mathrm{L} \mathrm{HCl}$ solution at room temperature. After addition of $8.5 \mathrm{~g}$ of tetraethyl orthosilicate (TEOS), the solution was kept at $40{ }^{\circ} \mathrm{C}$ for prehydrolysis, and then a specific amount of APTES was slowly added to the solution. The resulting mixture was stirred at $40{ }^{\circ} \mathrm{C}$ for $20 \mathrm{~h}$ and then aged at $90{ }^{\circ} \mathrm{C}$ for $24 \mathrm{~h}$. APTES-functionalized SBA-15 samples (APTES- SBA-15) were prepared with $0.1,0.2,0.5,0.8,1.0$, and $1.6 \mathrm{~g}$ of APTES, and denoted by AS- $n(n=0.1,0.2,0.5,0.8,1.0,1.6)$. The solid product was recovered by filtration and dried at room temperature overnight. Template removal from the as-synthesized material was conducted by refluxing in 95\% ethanol for $24 \mathrm{~h}$ (1.5 g of as-synthesized material per $400 \mathrm{ml}$ of ethanol). Finally, the samples were filtered, washed several times with water and ethanol, and dried at $50^{\circ} \mathrm{C}$.

A typical process for the immobilization of $\mathrm{H}_{3} \mathrm{PW}_{12} \mathrm{O}_{40}$ within the modified SBA-15 channels was carried out as follows: AS- $n$ samples ( $2 \mathrm{~g}$ ) were stirred in $5 \mathrm{ml}$ of an aqueous solution containing $6.5 \times 10^{-4} \mathrm{~mol}$ of $\mathrm{H}_{3} \mathrm{PW}_{12} \mathrm{O}_{40}\left(\mathrm{PW}_{12}\right)$ at $60^{\circ} \mathrm{C}$ for $8 \mathrm{~h}$. The resulting solid $\left(\mathrm{PW}_{12} / \mathrm{AS}-n\right)$ was then filtered, washed three times with methanol to remove unanchored $\mathrm{PW}_{12}$, and dried at $100{ }^{\circ} \mathrm{C}$ for $3 \mathrm{~h}$. To investigate the effects of calcination temperature, the immobilized samples were further separately treated at $100,400,600$, and $800{ }^{\circ} \mathrm{C}$. The calcined samples were denoted by PW12/AS- $n-T(T=100,400,600,800$ ${ }^{\circ} \mathrm{C}$.

\subsection{Characterization}

Elemental analysis was carried out using a Thermo Ele- mental IRIS Intrepid inductively coupled plasma atomic emission spectrometer and an Elementar Vario EL III microanalyzer. IR spectra were recorded on a Nicolet AVATAR 360 IR spectrometer using $\mathrm{KBr}$ pellets. The specific surface areas, pore diameters, and pore volumes of the samples were determined from $\mathrm{N}_{2}$ adsorption isotherms measured using a Micromeritics Tristar 3000 instrument. The NMR experiments were obtained using a Bruker Avance DSX 300 spectrometer. ${ }^{29}$ Si magic-angle spinning (MAS) NMR spectra were obtained at $59.6 \mathrm{MHz}$ with a $90^{\circ}$ pulse and a $600 \mathrm{~s}$ recycle delay at a spinning rate of ca. 4 kHz. ${ }^{1} \mathrm{H}$-decoupled ${ }^{31} \mathrm{P}$ MAS NMR spectra were obtained at 121.5 $\mathrm{MHz}$ with a $30^{\circ}$ pulse and a $20 \mathrm{~s}$ recycle delay at a spinning rate of ca. $12 \mathrm{kHz}$. XRD patterns were recorded on a Bruker D8 Advanced X-ray diffractometer using $\mathrm{Cu} K_{\alpha}$ radiation with a voltage of $40 \mathrm{kV}$ and a current of $40 \mathrm{~mA}$. TEM measurements were performed on a JEOL JEM-2011 transmission electron microscopy. The identification of reaction products was performed on a Finnigan Voyager gas chromatography/mass spectrometer (GC-MS) instrument. Samples were quantified on a GC-122 with an Alltech EC-5 capillary column.

\subsection{Catalytic reaction}

Catalytic tests were performed by adding $7.5 \mathrm{~g}$ of acetonitrile, $2.5 \mathrm{ml}$ (24.3 mmol) of $30 \% \mathrm{H}_{2} \mathrm{O}_{2}, 0.838 \mathrm{~g}$ ( $\left.10 \mathrm{mmol}\right)$ of cyclohexene, $0.100 \mathrm{~g}$ of $\mathrm{PW}_{12} / \mathrm{AS}-n-T$, and $2 \mathrm{ml}$ of $n$-hexane as the internal standard to a round-bottomed flask fitted with a reflux condenser. The mixture was stirred at $80{ }^{\circ} \mathrm{C}$ for $4 \mathrm{~h}$. On completion of the reaction, the catalyst was separated by centrifugation. The liquid products were analyzed by GC.

\section{Results and discussion}

\subsection{Characterization results of AS- $n$ and $P W_{12} / A S-n-T$}

The grafting of APTES in the SBA-15 channels was confirmed by NMR spectroscopy. A typical ${ }^{29}$ Si MAS NMR spectrum of AS-1.0 before immobilization of $\mathrm{PW}_{12}$ is shown in Fig. 1. The three distinct resonance peaks at $\delta=-89.7,-100.5$, and -109.7 are attributed to the $\mathrm{Q}^{2}, \mathrm{Q}^{3}$, and $\mathrm{Q}^{4}$ silicon atoms $\left(\mathrm{Q}^{n}=\right.$ $\left.\mathrm{Si}(\mathrm{OSi})_{n}(\mathrm{OH})_{4-n}, n=2-4\right)$, respectively, and the two other peaks, at $\delta=-55.7$ and -66.1 , are attributed to the $\mathrm{T}^{2}$ and $\mathrm{T}^{3}$ silicon atoms $\left(\mathrm{T}^{m}=\mathrm{RSi}(\mathrm{OSi})_{m}(\mathrm{OH})_{3-m}, m=2,3\right)$, respectively $[38,39]$.

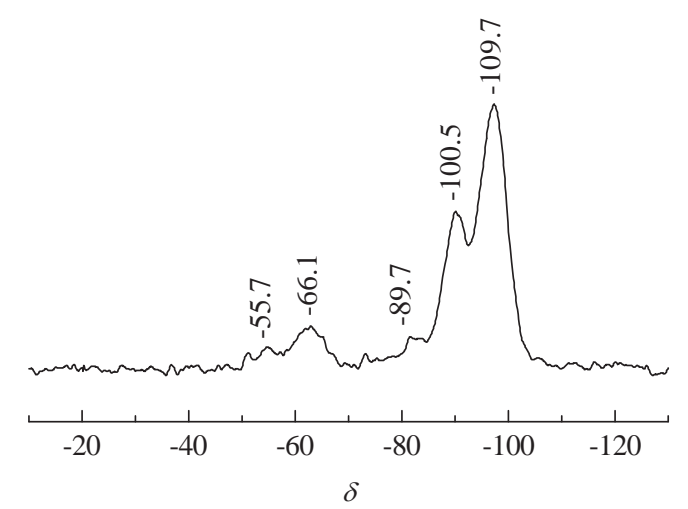

Fig. 1. ${ }^{29} \mathrm{Si}$ MAS NMR spectrum of AS-1.0 before immobilization of $\mathrm{PW}_{12}$. 
Table 1

$\mathrm{N}$ and $\mathrm{W}$ contents and molar ratios of APTES to $\mathrm{PW}_{12}$ of PW $\mathrm{PW}_{12} / \mathrm{AS}-n-100$ samples.

\begin{tabular}{lccc}
\hline \multirow{2}{*}{ Sample } & \multicolumn{2}{c}{ Element content $(\mathrm{wt} \%)$} & \multirow{2}{*}{$\begin{array}{c}\text { APTES/PW } \\
\text { molar ratio }\end{array}$} \\
\cline { 2 - 3 } & $\mathrm{N}$ & $\mathrm{W}$ & 4.32 \\
$\mathrm{PW}_{12} / \mathrm{AS}-0.1-100$ & 0.17 & 6.20 & 6.43 \\
$\mathrm{PW}_{12} / \mathrm{AS}-0.2-100$ & 0.49 & 12.00 & 9.99 \\
$\mathrm{PW}_{12} / \mathrm{AS}-0.5-100$ & 0.92 & 14.51 & 13.68 \\
$\mathrm{PW}_{12} / \mathrm{AS}-0.8-100$ & 1.57 & 18.07 & 13.09 \\
$\mathrm{PW}_{12} / \mathrm{AS}-1.0-100$ & 1.82 & 21.90 & 11.16 \\
$\mathrm{PW}_{12} / \mathrm{AS}-1.6-100$ & 2.58 & 36.40 & \\
\hline
\end{tabular}

The appearance of $\mathrm{T}^{m}$ peaks confirms that the silane organic moieties are incorporated as part of the silica wall structure and most of the grafted functional groups are bound to the surface. The intensity ratio $\mathrm{T}^{m} /\left(\mathrm{T}^{m}+\mathrm{Q}^{n}\right)$ is ca. 0.13 for AS-1.0, in good agreement with that theoretically expected on the basis of the APTES content in the initial mixture, suggesting that nearly all the APTES was incorporated with the TEOS to form APTES-SBA-15.

Elemental analysis was performed to determine the amount of APTES incorporated in SBA-15 and to confirm whether PW 12 was introduced onto APTES-SBA-15. The $\mathrm{N}$ and $\mathrm{W}$ contents and the molar ratios of APTES to $\mathrm{PW}_{12}$ deduced from the N/W ratios are listed in Table 1 . The amount of PW 12 clusters attached to the aminosilylated support increased with increasing content of amino groups. This indicates that the polyacids are held on the silica surface via electrostatic interactions. A considerable amount of APTES is not combined well with the PW 12 clusters because of the steric hindrance of the Keggin polyanions, which leads to molar ratios of APTES to $\mathrm{PW}_{12}$ greater than the theoretical value of 3 .

IR spectroscopy was used to determine the presence of $\mathrm{PW}_{12}$ clusters within the SBA-15 channels [40]. The characteristic IR fingerprints of bulk $\mathrm{PW}_{12}$ and $\mathrm{PW}_{12} / \mathrm{AS}-1.6-T$ in the region from 1100 to $700 \mathrm{~cm}^{-1}$ (Table 2) are attributed to the vibrations of $\mathrm{P}-\mathrm{O}$ in the central $\mathrm{PO}_{4}$ unit, and of $\mathrm{W}=\mathrm{O}$ and $\mathrm{W}-\mathrm{O}-$ $\mathrm{W}$ in $\mathrm{PW}_{12}$. The bands at $900-1050 \mathrm{~cm}^{-1}$ are partially obscured by the presence of silica [41]. These characteristic IR absorption data are very useful in identifying the structural features of polyoxometalates (POMs) incorporated into the mesoporous channels. It can be seen that the vibration bands of PW 12 /AS-1.6- $T\left(T=100,400{ }^{\circ} \mathrm{C}\right)$ are similar to those of the corresponding bulk $\mathrm{PW}_{12}$, suggesting that the Keggin structures of the POMs remained intact after immobilization on the mesoporous silica surface and calcining at a low temperature (Fig. 2). For the $\mathrm{PW}_{12} / \mathrm{AS}-1.6-600$ sample, the specific bands shift obviously, indicating that the Keggin structure has changed after being calcined at $600^{\circ} \mathrm{C}$.

The 31P MAS NMR spectra of PW $12 / A S-1.6-100$ and $\mathrm{PW}_{12} / \mathrm{AS}-1.6-400$ are shown in Fig. 3. The peak at ca. $\delta=-15$ in

Table 2

IR bands of $\mathrm{PW}_{12}$ and $\mathrm{PW}_{12} / \mathrm{AS}-1.6-T$.

\begin{tabular}{lcccc}
\hline Sample & $v_{\text {as }}(\mathrm{P}-0) / \mathrm{cm}^{-1}$ & $v_{\text {as }}(\mathrm{W}=0) / \mathrm{cm}^{-1}$ & $v_{\text {as }}(\mathrm{W}-\mathrm{O}-\mathrm{W}) / \mathrm{cm}^{-1}$ \\
\hline $\mathrm{PW}_{12}$ & 1081 & 983 & 893 & 814 \\
$\mathrm{PW}_{12} / \mathrm{AS}-1.6-100$ & 1083 & 982 & 897 & 810 \\
$\mathrm{PW}_{12} / \mathrm{AS}-1.6-400$ & 1082 & 979 & 901 & 814 \\
$\mathrm{PW}_{12} / \mathrm{AS}-1.6-600$ & 1092 & 921 & 816 & 776 \\
\hline
\end{tabular}

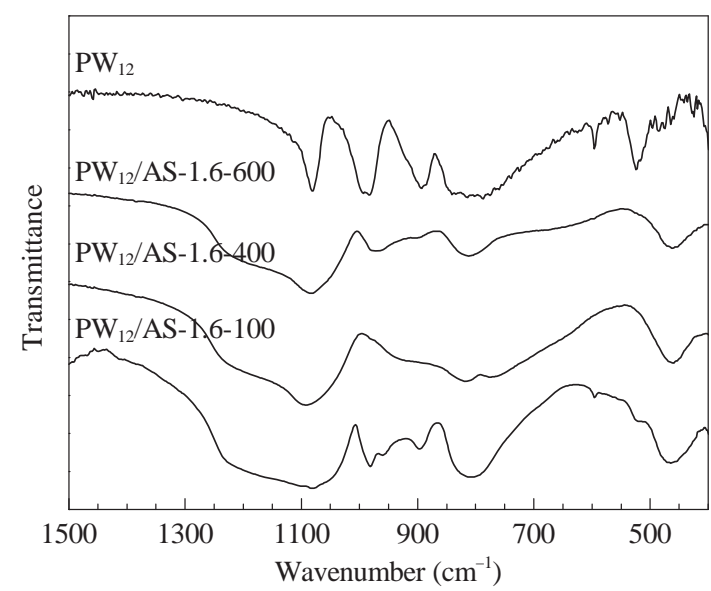

Fig. 2. IR spectra of bulk $\mathrm{PW}_{12}$ and $\mathrm{PW}_{12} / \mathrm{AS}-1.6-T$.

both samples is slightly perturbed from that of pure $\mathrm{H}_{3} \mathrm{PW}_{12} \mathrm{O}_{40}$ [42], indicating retention of the Keggin structure. An additional weak peak at $\delta=-13.0$ in $\mathrm{PW}_{12} / \mathrm{AS}-1.6-100$ may be assigned to a small portion of a partially degraded cluster, which is possibly formed as a result of the basicity of the surface amines. This additional peak becomes stronger and broader after treatment at higher temperatures, which is possibly the result of complicated interactions between the POM and the support. However, the ${ }^{31} \mathrm{P}$ MAS NMR results indicate that PW 12 /AS-1.6-400 retains a high content of phosphorus and the majority of the Keggin structure.

\subsection{Effects of different loadings and treatment temperatures}

Typical low-angle XRD patterns of catalysts with the same $\mathrm{PW}_{12}$ loading but treated at different temperatures, $\mathrm{PW}_{12} / \mathrm{AS}-0.2-T(T=100,400,600,800)$, are shown in Fig. 4 . All four samples have the same APTES and PW 12 contents. The $\mathrm{PW}_{12} / \mathrm{AS}-0.2-T\left(T=100,400,600{ }^{\circ} \mathrm{C}\right)$ samples exhibit three peaks, which can be indexed as the characteristic (100), (110), and (200) diffractions of hexagonal mesoporous SBA-15, indicating that these samples consist of well-ordered channels [29]. The $\mathrm{PW}_{12} / \mathrm{AS}-0.2-800$ sample shows the weakest peaks, and the intensities of all the diffraction peaks drop significantly; this

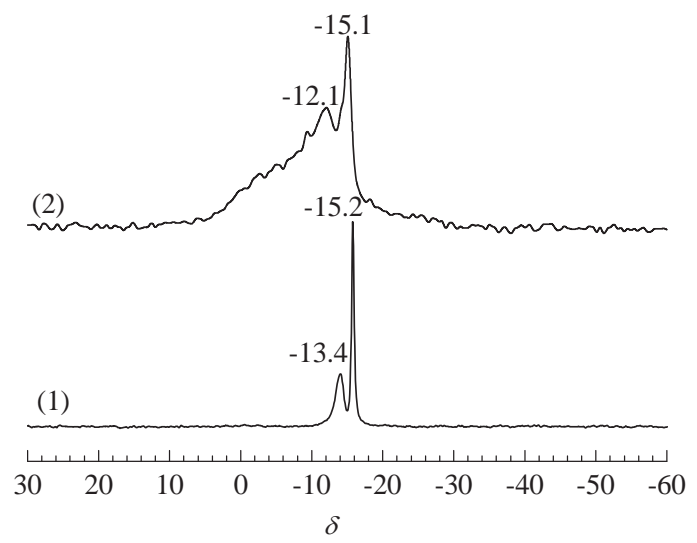

Fig. 3. ${ }^{31} \mathrm{P}$ MAS NMR spectra of $\mathrm{PW}_{12} / \mathrm{AS}-1.6-100$ (1) and $\mathrm{PW}_{12} / \mathrm{AS}-1.6-400$ (2). 


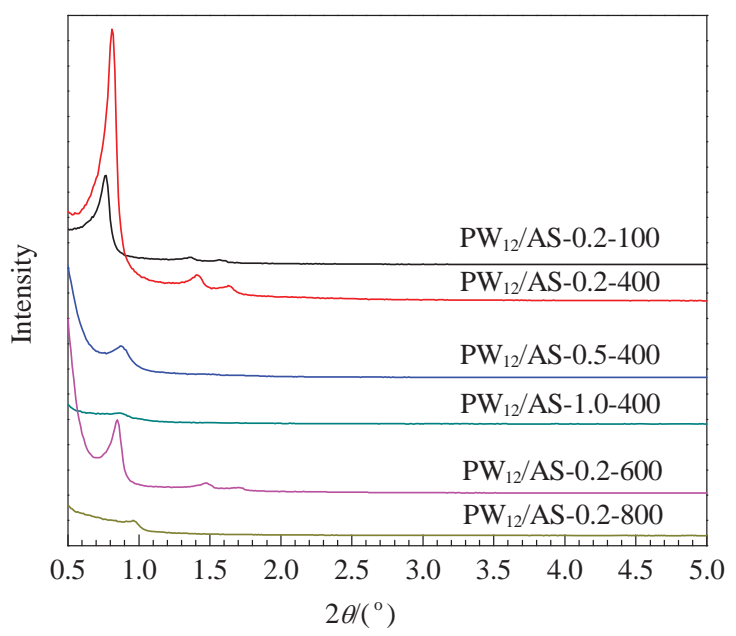

Fig. 4. Low-angle XRD patterns of $\mathrm{PW}_{12} / \mathrm{AS}-0.2-T$ and $\mathrm{PW}_{12} / \mathrm{AS}-n-400$.

could be caused by the collapse of the typical SBA-15 ordered structure under high-temperature treatment. With increasing treatment temperature, the diffraction peaks shift slightly towards larger angles, indicating a slight shrinkage of the cell dimensions during calcination.

The effects of different contents of APTES and PW 12 on the mesoporous structure are also shown in Fig. 4. Three samples, $\mathrm{PW}_{12} / \mathrm{AS}-n-400(n=0.2,0.5,1.0)$, were treated at the same temperature $\left(400^{\circ} \mathrm{C}\right)$. On increasing the APTES and PW 12 contents, the diffraction peaks shift towards larger angles and their intensities decrease. It can be concluded that the primary structure of SBA-15 is well maintained after aminosilylation and immobilization of $\mathrm{PW}_{12}$, but an increase in the $\mathrm{PW}_{12}$ loading inside the SBA-15 channels results in pore filling of the host material with $\mathrm{PW}_{12}$.

High-angle XRD patterns of typical samples, $\mathrm{PW}_{12}$ /AS-0.5-T $\left(T=400,600,800{ }^{\circ} \mathrm{C}\right)$, are displayed in Fig. 5 . It can be clearly observed that several diffraction peaks appear when the samples are treated at high temperatures $\left(600\right.$ and $\left.800{ }^{\circ} \mathrm{C}\right)$, indicating decomposition of $\mathrm{PW}_{12}$ to form monoclinic tungstic oxide $(a=0.7306 \mathrm{~nm}, b=0.7540 \mathrm{~nm}, c=0.7692 \mathrm{~nm}$; JCPDS 72-0677). However, there is no diffraction peak in the $\mathrm{PW}_{12}$ /AS-0.5-400 sample, which means that the Keggin struc-

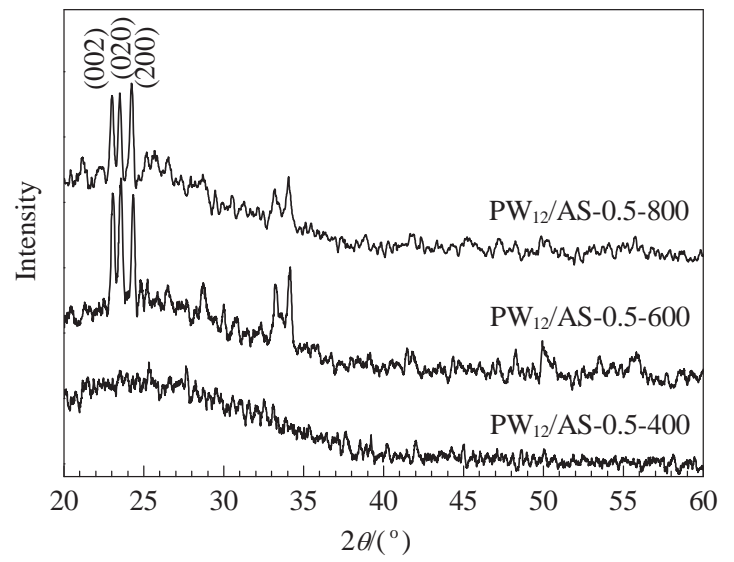

Fig. 5. XRD patterns of $\mathrm{PW}_{12} / \mathrm{AS}-0.5-T$.

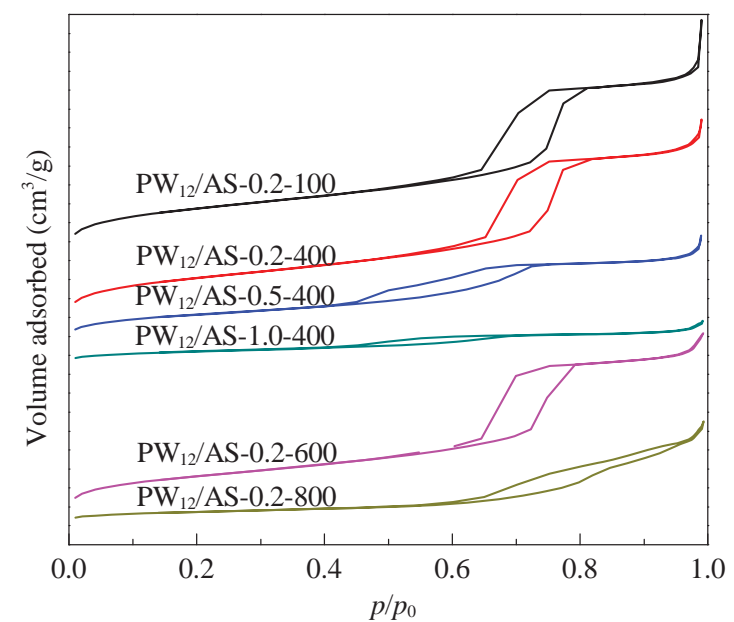

Fig. 6. $\mathrm{N}_{2}$ adsorption-desorption isotherms of $\mathrm{PW}_{12} / \mathrm{AS}-0.2-T$ and $\mathrm{PW}_{12} / \mathrm{AS}-n-400$.

ture remains intact, as observed in the IR spectra.

The $\mathrm{N}_{2}$ adsorption isotherms of $\mathrm{PW}_{12} / \mathrm{AS}-0.2-T(T=100$, $400,600,800^{\circ} \mathrm{C}$ ) in Fig. 6 are classified as type IV, which is the typical hysteresis loop of mesoporous materials [29]. The surface-modified and $\mathrm{PW}_{12}$-introduced samples retain the same isotherm shape for the samples from $\mathrm{PW}_{12} / \mathrm{AS}-0.2-100$ to $\mathrm{PW}_{12} / \mathrm{AS}-0.2-600$. However, the shape of the hysteresis loop of $\mathrm{PW}_{12} / \mathrm{AS}-0.2-800$ changes significantly; this is caused by loss of the ordered SBA-15 structure. The inflection point of the step is shifted to low $p / p_{0}$ with increasing calcination temperature, attributed to a decrease in pore size. Contraction of the channels at high temperature accounted for the decreases in pore volume, pore size, and surface area, listed in Table 3. The effects of different APTES and PW 12 contents on the mesoporous structure are shown in Fig. 6. The hysteresis loops of PW12/AS-0.5-400 and PW12/AS-1.0-400 decrease obviously in comparison with that of $\mathrm{PW}_{12} / \mathrm{AS}-0.2-400$; this is caused by filling of the channels with larger amounts of APTES and PW $\mathrm{PW}_{12}$ The variations in the physicochemical parameters listed in Table 3 indicate that the amino groups of APTES and PW $\mathrm{PW}_{12}$ are impregnated into the SBA-15 pore channels. These results are consistent with the low-angle XRD patterns.

The TEM images of $\mathrm{PW}_{12} / \mathrm{AS}-1.0-400$ further demonstrate that the hexagonal ordered channel structure of SBA-15 was not significantly changed after aminosilylation, immobilization of PW 12 in the channels, and thermal treatment. It can be clearly seen in Fig. 7 that the $\mathrm{PW}_{12}$ clusters were highly dispersed inside the modified SBA-15 host.

Table 3

Physicochemical properties of PW $\mathrm{PW}_{12} / \mathrm{AS}-0.2-T$ and PW $12 / \mathrm{AS}-n-400$.

\begin{tabular}{lccc}
\hline Sample & $\begin{array}{c}\text { BET surface } \\
\text { area }\left(\mathrm{m}^{2} / \mathrm{g}\right)\end{array}$ & $\begin{array}{c}\text { BJH pore } \\
\text { diameter }(\mathrm{nm})\end{array}$ & $\begin{array}{c}\text { BJH pore } \\
\text { volume }(\mathrm{ml} / \mathrm{g})\end{array}$ \\
\hline $\mathrm{PW}_{12} / \mathrm{AS}-0.2-100$ & 585 & 7.7 & 1.02 \\
$\mathrm{PW}_{12} / \mathrm{AS}-0.2-400$ & 573 & 6.9 & 0.89 \\
$\mathrm{PW}_{12} / \mathrm{AS}-0.5-400$ & 384 & 5.6 & 0.48 \\
$\mathrm{PW}_{12} / \mathrm{AS}-1.0-400$ & 225 & 5.4 & 0.27 \\
$\mathrm{PW}_{12} / \mathrm{AS}-0.2-600$ & 493 & 6.7 & 0.82 \\
$\mathrm{PW}_{12} / \mathrm{AS}-0.2-800$ & 132 & 10.2 & 0.43 \\
\hline
\end{tabular}




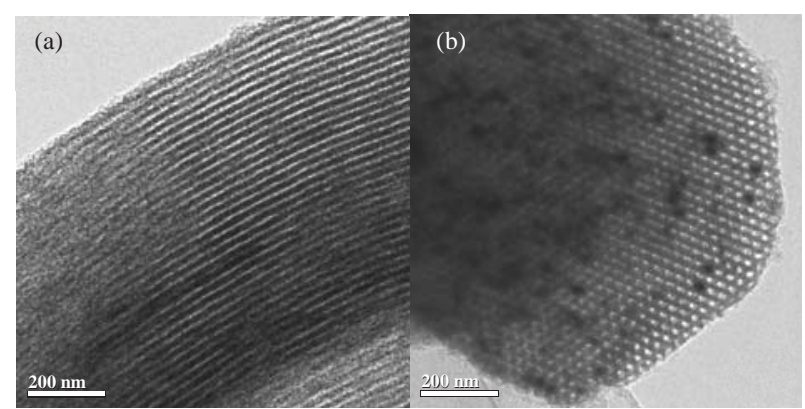

Fig. 7. TEM images of $\mathrm{PW}_{12} / \mathrm{AS}-1.0-400$, perpendicular (a) and parallel (b) to the channel direction of SBA-15.

The IR and 31P MAS NMR spectra show interactions between the $\mathrm{PW}_{12}$ clusters and the supports and retention of the Keggin structure. TEM images supply direct proof of distribution of the $\mathrm{PW}_{12}$ clusters inside the mesoporous silica. The XRD patterns and $\mathrm{N}_{2}$ adsorption isotherms show that the support preserves its ordered mesoporous structure under thermal treatment up to $600{ }^{\circ} \mathrm{C}$.

\subsection{Catalytic tests}

The epoxidation of cyclohexene with $30 \% \mathrm{H}_{2} \mathrm{O}_{2}$ was chosen as a model reaction to compare the behaviors of different catalysts. The yields of cyclohexene oxide after $4 \mathrm{~h}$ are shown in Fig.
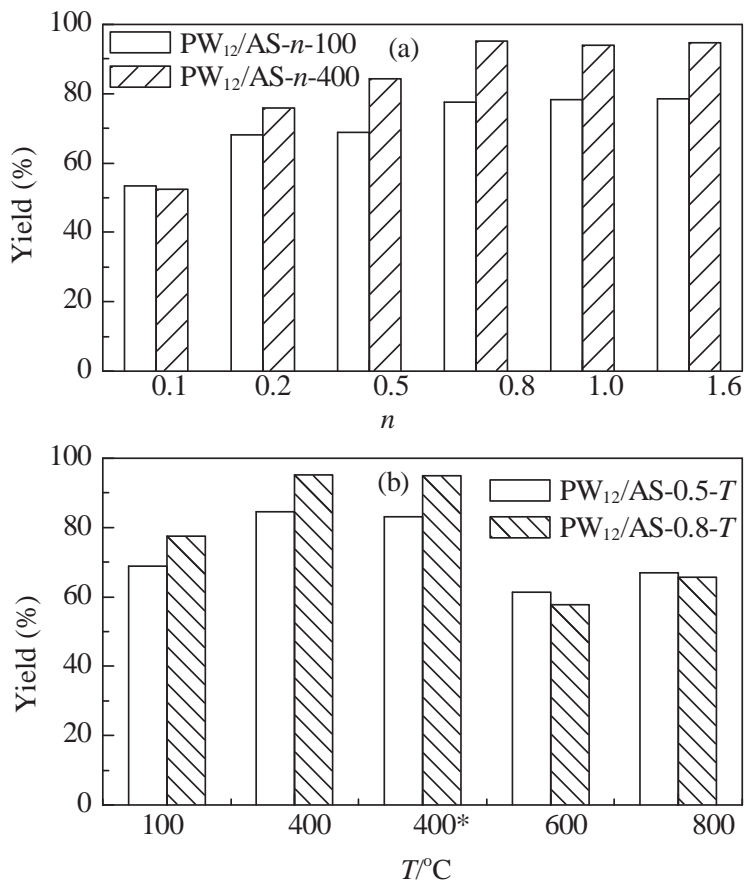

Fig. 8. Comparison of catalytic activities in epoxidation of cyclohexene with $30 \% \quad \mathrm{H}_{2} \mathrm{O}_{2}$ over PW $12 / \mathrm{AS}-n-T$ catalysts. (a) Two sets of $\mathrm{PW}_{12} / \mathrm{AS}-n-100$ and $\mathrm{PW}_{12} / \mathrm{AS}-n-400(n=0.1,0.2,0.5,0.8,1.0,1.6)$ catalysts with different $\mathrm{PW}_{12}$ loadings; (b) Two sets of PW $12 / \mathrm{AS}-0.5-T$ and $\mathrm{PW}_{12} / \mathrm{AS}-0.8-T\left(T=100,400,600,800{ }^{\circ} \mathrm{C}\right)$ catalysts calcined at different temperatures. Reaction conditions: $7.5 \mathrm{~g}$ of acetonitrile, $2.5 \mathrm{ml}$ (24.3 mmol) of $\mathrm{H}_{2} \mathrm{O}_{2}, 0.838 \mathrm{~g}(10 \mathrm{mmol})$ of cyclohexene, $0.100 \mathrm{~g}$ of $\mathrm{PW}_{12} / \mathrm{AS}-n-T, 2 \mathrm{ml}$ of $n$-hexane (internal standard), $80^{\circ} \mathrm{C}, 4$ h. ${ }^{*}$ Recycled after the fifth run.
8. The samples exhibit remarkable catalytic activities. No other oxidation product was observed, indicating that the selectivity for cyclohexene oxide was almost $100 \%$ [43]. The yields of cyclohexene oxide using the PW12/AS- $n-100(n=0.1,0.2,0.5$, $0.8,1.0,1.6)$ samples (Fig. 8(a)) are higher than those over Aerosil-Ti(OiPr), TiSBA-15, and Ti-MCM-41 reported in the literature [44-46].

As shown in Fig. 8(b), for catalysts with the same PW 12 contents, different calcination temperatures affect the catalytic performance significantly. The yields over $\mathrm{PW}_{12} / \mathrm{AS}-0.5-T$ and $\mathrm{PW}_{12} / \mathrm{AS}-0.8-T(T=100,400,600,800)$ were chosen to compare the different catalytic behaviors. The catalysts calcined at $100{ }^{\circ} \mathrm{C}$ always gave relatively low yields, but the yields increased quickly for those calcined at $400{ }^{\circ} \mathrm{C}$. When the calcination temperature was increased to $600{ }^{\circ} \mathrm{C}$, the yields decreased significantly, and the catalysts calcined at $800^{\circ} \mathrm{C}$ exhibited similar activities to those calcined at $600^{\circ} \mathrm{C}$. As shown in Fig. 5, the Keggin structures of the POMs remained intact on the support when the calcination temperature was $400{ }^{\circ} \mathrm{C}$, whereas the samples treated at 600 and $800{ }^{\circ} \mathrm{C}$ decomposed to the crystalline phase of $\mathrm{WO}_{3}$. The above catalytic results clearly demonstrate that $\mathrm{PW}_{12}$ could be the most active species under the present reaction conditions. Thus, as shown in Fig. 8(a), the conversion and epoxide yield increase with increasing $\mathrm{PW}_{12}$ loading.

Catalyst recycling tests were carried out on $\mathrm{PW}_{12} / \mathrm{AS}-0.5-400$ and $\mathrm{PW}_{12} / \mathrm{AS}-0.8-400$. After the reaction, the catalyst was separated from the reaction mixture by centrifugation and calcined at $400{ }^{\circ} \mathrm{C}$ for reuse. As shown in Fig. 8(b), there was nearly no loss of activity after five cycles, indicating that the catalysts have high reusability. In the ${ }^{31} \mathrm{P}$ NMR study, no signal was detected in the solution after reaction for $4 \mathrm{~h}$ with PW 12 /AS-0.5-400 and $\mathrm{PW}_{12} / \mathrm{AS}-0.8-400$, showing that the loss of active species was negligible. In contrast, under the same reaction conditions, the conversion of cyclohexene decreased significantly over $\mathrm{PW}_{12} / \mathrm{AS}-0.5-100$, and the $31 \mathrm{P}$ NMR signal, although weak, could be detected in the filtered reaction solution. Calcination therefore not only enhances the catalytic activity, but also prevents catalyst leaching.

\section{Conclusions}

A series of mesoporous-SBA-15-immobilized 12-phosphotungstic acids $\left(\mathrm{H}_{3} \mathrm{PW}_{12} \mathrm{O}_{40}\right)$, with various amounts of incorporated heteropoly acid, were fabricated by directly immobilizing $\mathrm{H}_{3} \mathrm{PW}_{12} \mathrm{O}_{40}$ on the channels of SBA-15 co-synthesized with APTES. In this preparation method, the calcination temperature plays an important role in increasing the catalytic activity. The catalysts calcined at $400{ }^{\circ} \mathrm{C}$ showed high reactivities and reusabilities in the liquid-phase epoxidation of cyclohexene with $\mathrm{H}_{2} \mathrm{O}_{2}$ as the oxidant. These results are promising for further applications in other reactions because of the heterogenized homogeneous characters of the heteropoly acids.

\section{References}

[1] Ichihara J, Iteya K, Kambara A, Sasaki Y. Catal Today, 2003, 87: 163 


\title{
Graphical Abstract
}

Chin. J. Catal., 2013, 34: 193-199 doi: 10.1016/S1872-2067(11)60459-2

Catalytic epoxidation of cyclohexene over mesoporous-silica immobilized Keggin-type tungstophosphoric acid

CAI Wenjia, ZHOU Yan, BAO Renlie, YUE Bin*, HE Heyong* Fudan University

A simple method was used to prepare mesoporous-silica- immobilized Keggin-type tungstophosphoric acid. The resulting catalysts showed high catalytic activities and reusabilities in heterogeneous oxidation of cyclohexene using $\mathrm{H}_{2} \mathrm{O}_{2}$ as the oxidant.

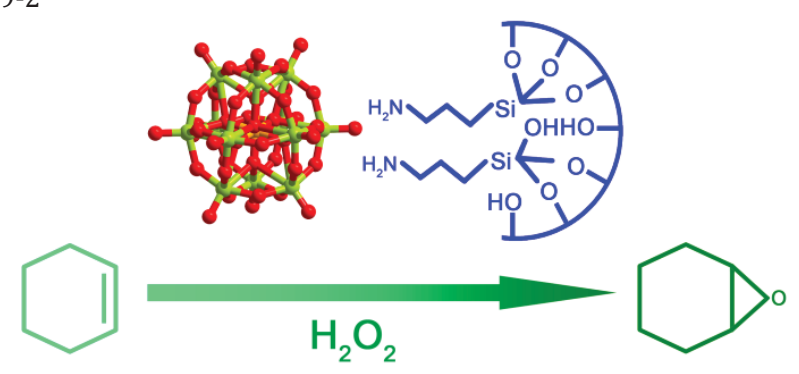

[2] Watanabe Y, Yamamoto K, Tatsumi T.J Mol Catal A, 1999, 145: 281

[3] Kasai J, Nakagawa Y, Uchida S, Yamaguchi K, Mizuno N. Chem Eur J, 2006, 12: 4176

[4] Kamata K, Sugahara K, Yonehara K, Ishimoto R, Mizuno N. Chem Eur J, 2011, 17: 7549

[5] Patel K, Tripuramallu B K, Patel A. Eur J Inorg Chem, 2011: 1871

[6] Tang J Y, Wang L, Liu G, Liu Y, Hou Y Z, Zhang W X, Jia M J, Thiel W R. J Mol Catal A, 2009, 313: 31

[7] Miao Y X, Yang X L, Guo L H. Chin J Catal (苗永霞, 杨新丽, 郭丽红. 催化学报), 2012, 33: 711

[8] Adam W, Alsters P L, Neumann R, Saha-Möller C R, Sloboda-Rozner D, Zhang R. J Org Chem, 2003, 68: 1721

[9] Adam W, Herold M, Hill C L, Saha-Möller C R. Eur J Org Chem, 2002: 941

[10] Vasylyev M V, Neumann R.J Am Chem Soc, 2004, 126: 884

[11] Pai Z P, Kochubey D I, Berdnikova P V, Kanazhevskiy V V, Prikhod'ko I Y, Chesalov Y A. J Mol Catal A, 2010, 332: 122

[12] Yang X L, Dai W L, Gao R H, Chen H, Li H X, Cao Y, Fan K N. J Mol Catal A, 2005, 241: 205

[13] Lü H Y, Gao J B, Jiang Z X, Jing F, Yano Y X, Wang G, Li C. J Catal, 2006, 239: 369

[14] Das D P, Parida K M. Appl Catal A, 2006, 305: 32

[15] Nowińska K, Fórmaniak R, Kaleta W, Waclaw A. Appl Catal A, 2003, 256: 115

[16] Collins F M, Lucy A R, Sharp C. J Mol Catal A, 1997, 117: 397

[17] Te M, Fairbridge C, Ring Z. Appl Catal A, 2001, 219: 267

[18] Aubry C, Chottard G, Platzer N, Brégeault J M, Thouvenot R, Chauveau F, Huet C, Ledon H. Inorg Chem, 1991, 30: 4409

[19] Ding Y, Gao Q Li G X, Zhang H P, Wang J M, Yan L, Suo J S. J Mol Catal A, 2004, 218: 161

[20] Ghanbari-Siahkali A, Philippou A, Dwyer J, Anderson M W. Appl Catal A, 2000, 192: 57

[21] Verhoef M J, Kooyman P J, Peters J A, van Bekkum H. Microporous Mesoporous Mater, 1999, 27: 365

[22] Kozhevnikov I V, Sinnema A, Jansen R J J, Pamin K, Van Bekkum H. Catal Lett, 1995, 30: 241

[23] Atia H, Armbruster U, Martin A.J Catal, 2008, 258: 71

[24] Yadav G D, Manyar H G. Microporous Mesoporous Mater, 2003, 63: 85

[25] Li H X, Yin H B, Jiang T S, Hu T J, Wu J, Wada Y J. Catal Commun,

\section{6, 7: 778}

[26] Ivanov A V, Vasina T V, Nissenbaum V D, Kustov L M, Timofeeva M N, Houzvicka J I. Appl Catal A, 2004, 259: 65

[27] Tsukamoto D, Ikeda M, Shiraishi Y, Hara T, Ichikuni N, Tanaka S, Hirai T. Chem Eur J, 2011, 17: 9816

[28] Hua D R, Chen S L, Yuan G M, Wang Y L, Zhao Q F, Wang X L, Fu B. Micropor Mesopor Mater, 2011, 143: 320

[29] Zhao D Y, Feng J L, Huo Q S, Melosh N, Fredrickson G H, Chmelka B F, Stucky G D. Science, 1998, 279: 548

[30] Zhao D Y, Huo Q S, Feng J L, Chmelka B F, Stucky G D. J Am Chem Soc, 1998, 120: 6024

[31] Zhu K K, He H Y, Xie S H, Zhang X, Zhou W Z, Jin S L, Yue B. Chem Phys Lett, 2003, 377: 317

[32] Zhu K K, Bin Y, Xie S H, Zhang S Y, Zhang B, Jin S L, He H Y. Chin J Chem, 2004, 22: 33

[33] Impens N R E N, van der Voort P, Vansant E F. Microporous Mesoporous Mater, 1999, 28: 217

[34] Zhou Y, Bao R L, Yue B, Gu M, Pei S P, He H Y.J Mol Catal A, 2007, 270: 50

[35] Zhou Y, Yue B, Bao R L, Liu S X, He H Y. Chin J Chem, 2006, 24: 1001

[36] Chong A S M, Zhao X S, Kustedjo A T, Qiao S Z. Microporous Mesoporous Mater, 2004, 72: 33

[37] Chong A S M, Zhao X S.J J Phys Chem B, 2003, 107: 12650

[38] Llusar M, Monrós G, Roux C, Pozzo J L, Sanchez C. J Mater Chem, 2003, 13: 2505

[39] Wang Y Q, Yang C M, Zibrowius B, Spliethoff B, Lindén M, Schüth F. Chem Mater, 2003, 15: 5029

[40] Choi S M, Wang Y, Nie Z M, Liu J, Peden C H F. Catal Today, 2000, 55: 117

[41] Li D F, Guo Y H, Hu C W, Mao L, Wang E. Appl Catal A, 2002, 235: 11

[42] Kozhevnikov I V, Kloetstra K R, Sinnema A, Zandbergen H W, vanBekkum H. J Mol Catal A, 1996, 114: 287

[43] Johnson B J S, Stein A. Inorg Chem, 2001, 40: 801

[44] Fraile J M, García J I, Mayoral J A, Vispe E. Appl Catal A, 2003, 245: 363

[45] Sazo V, López C M, De Quesada M, Vieira J M. Catal Today, 2011, 172: 8

[46] Vernimmen J, Guidotti M, Silvestre-Albero J, Jardim E O, Mertens M, Lebedev O I, Van Tendeloo G, Psaro R, Rodríguez- Reinoso F, Meynen V, Cool P. Langmuir, 2011, 27: 3618

\section{介孔硅负载 Keggin 型铇磷酸催化环己烯环氧化}

\author{
蔡雯佳, 周 琰, 包任烈, 岳 斌*, 贺鹤勇
}

复旦大学化学系, 上海市分子催化和功能材料重点实验室, 上海 200433 
摘要: 采用共合成法制备了一系列不同硅氨基含量的介孔氧化硅 SBA-15, 在其孔道中引入 Keggin 型钨磷酸, 且其含量随硅氨基含 量的增加而增加. 考察了不同处理温度下杂多酸的热稳定性, 发现焙烧后铇物种能在 SBA- 15 孔道内高度分散. 以 $\mathrm{H}_{2} \mathrm{O}_{2}$ 为氧化剂, 研究了该催化剂在环己烯环氧化反应中的催化活性, 考察了杂多酸负载量和焙烧温度对催化活性的影响. 结果表明, $400{ }^{\circ} \mathrm{C}$ 处理后 的铇磷酸催化剂具有高的反应活性和重复使用性能.

关键词: 12-磷铇酸; 硅氨基化; SBA-15; 环氧化; 环己烯

收稿日期: 2012-08-31. 接受日期：2012-09-18. 出版日期: 2013-01-20.

*通讯联系人. 电话: (021)65642779; 传真: (021)55665572; 电子信箱: yuebin@ @udan.edu.cn

\#通讯联系人. 电话: (021)65643916; 传真: (021)55665572; 电子信箱: heyonghe@ fudan.edu.cn

基金来源：国家重点基础研究发展计划 (973 计划, 2009CB623506); 国家自然科学基金 (21173050); 上海市重点学科建设项目 (B108).

本文的英文电子版由Elsevier出版社在ScienceDirect上出版(http://www.sciencedirect.com/science/journal/18722067).

\section{2nd International Congress on Catalysis for Biorefineries (CatBior 2013)}

September 22-25, 2013, Dalian, China

http://catbior2013.dicp.ac.cn

\section{Call For Papers}

\section{Congress Introduction}

The Organizing Committee cordially invites you to participate in the 2nd International Congress on Catalysis for Biorefineries to be held in Dalian from 22nd to 25th September, 2013. The International Congress on Catalysis for Biorefineries originated in Torremolinos, Málaga, Spain in 2011. The congress alternates worldwide in odd years. This international congress aims to create a platform for the scientific exchange of the views and latest research findings in the development of clean and efficient processes for the catalytic conversion of biomass into fuels and chemicals.

\section{Scopes}

This congress is devoted to fundamental and applied research on catalytic processes for biomass transformation without enzymatic process. The topical areas of interest include, but are not limited to:

a) Catalytic transformation of cellulose, hemicelluose, lignin, and raw biomass.

b) Catalytic transformation of carbohydrates and sugar-derived products.

c) Catalytic transformation of oil, fats, algae and oleo-derived chemicals.

d) Thermochemical transformations of biomass and related catalytic upgrading technologies for bio-oil.

\section{Publications}

The most significant and original works will be selected for publication in the special issues of Catalysis Today (http:// www.journals.elsevier.com/catalysis-today/) and Chinese Journal of Catalysis (http://www.sciencedirect.com/science/ journal/18722067) after a peer-review process.

\section{Key Dates:}

- Online abstract submission: February 1st, 2013

- Deadline for submission of abstracts: April 1st, 2013

- Abstract acceptance notification: May 1st, 2013

- Deadline for early bird registration: July 1st, 2013

- Conference: September 22nd-25th, 2013

\section{Scientific Correspondence}

Professor Tao Zhang

Chairman of the Organizing Committee

Director, Dalian Institute of Chemical Physics

Chinese Academy of Sciences

457 Zhongshan Road, Dalian 116023, China

Tel: +86-411-84379015; Fax: +86-411-84691570

E-mail: taozhang@dicp.ac.cn

Website: http://catbior2013.dicp.ac.cn

Professor Aiqin Wang

Vice-chairman of the Organizing Committee

Dalian Institute of Chemical Physics

Chinese Academy of Sciences

457 Zhongshan Road, Dalian 116023, China

Tel: +86-411-84379348; Fax: +86-411-84375940

E-mail: aqwang@dicp.ac.cn

\section{Conference General Contact:}

Dr. Changzhi Li

Secretary of the Organizing Committee

Dalian Institute of Chemical Physics

Chinese Academy of Sciences

457 Zhongshan Road, Dalian 116023, China

Tel: +86-411-84379738; Fax: +86-411-84375940

E-mail: catbior2013@dicp.ac.cn 